\title{
EARLY CAMBRIAN CHELICERATE ARTHROPOD FROM CHINA
}

BABCOCK*, Loren E., Dept. of Geological Sciences, The Ohio State University, Columbus, OH 43210, U.S.A.; CHANG, W. T. (ZHANG Wentang), Nanjing Institute of Geology and Palaeontology, Academia Sinica, Nanjing 210008, China

A new marine arthropod from the Chengjiang Lagerstätte (Yuanshan Member, Heilinpu Formation; Lower Cambrian) is interpreted as the oldest known representative of the Chelicerata. It increases the number of putative chelicerates from Cambrian rocks to three species, and extends the record of chelicerates into the Early Cambrian.

The new animal is reconstructed (Figure 1) from a single specimen that is intact except for head appendages of the right side, and part of the tail shield. It has a nonmineralized cuticle, a large trapezoidal head shield, an abdomen containing eight wide segments, and a large tail shield. Six pairs of appendages are attached ventrally to the head shield. The first pair of appendages is small and preoral; it is interpreted as a pair of chelicerae. The second pair of appendages is large, forwardly directed, and bears articulating spines along the medial side; it is interpreted as a pair of pedipalps. The fourth to sixth pairs of appendages are large, and have ovoid, paddle-like terminal podomeres; they are interpreted as swimming paddles. A large, appendage-like structure that has comb-like projections extends from the ventral side, and may represent a pectine. Alternatively, this structure may represent a gill branch of a biramous appendage. Indistinct raised areas on the cuticle suggest the positions of eyes at the anterolateral corners of the head shield, and gill plates ventrally on the anterior abdominal segments.

The new arthropod shows tagmosis into a head, abdomen, and tail, and has six pairs of jointed appendages (including probable chelicerae and pedipalps) that articulate with the head beneath a cardiac lobe. Together, these characters indicate it is a chelicerate. However, it has an unusual combination of primitive and derived characters. The presence of paddle-like appendages (appendage pairs three to six) and the large, paddle-like tail shield are all consistent with a marine habitat and relatively primitive phylogenetic position within the Chelicerata. The lack of differentiation into a distinct preabdomen and postabdomen is also consistent with that position. The comb-like structure, if it is regarded as a pectine (a synapomorphy of scorpions), suggests that the new animal shares a common ancestry with modern scorpions.

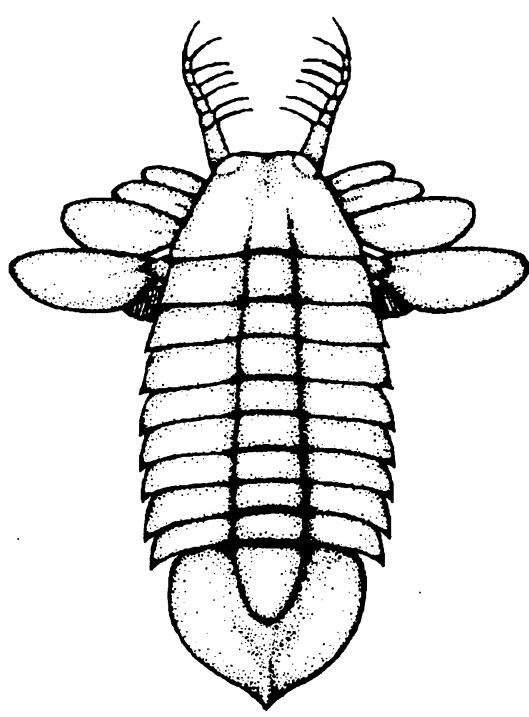

Figure 1. Preliminary reconstruction of new chelicerate arthropod from the Early Cambrian Chengiiang Biota of China, dorsal side; $\mathrm{x} 1$. 